\title{
CORRIGENDUM
}

\section{Reticulocalbin-2 enhances hepatocellular carcinoma proliferation via modulating the EGFR-ERK pathway}

D Ding, H Huang, W Jiang, W Yu, H Zhu, J Liu, H Saiyin, J Wu, H Huang, S Jiang and L Yu

Oncogene (2017) 36, 6747-6748; doi:10.1038/onc.2017.366

Correction to: Oncogene (2017) 36, 6691-6700; doi: 10.1038/onc. 2017.230; published online 24 July 2017

Following the publication of this article the authors noted errors in the labelling of Figures $1 \mathrm{c}$ and $\mathrm{d}$. The figure legends should be exchanged so that Figure $1 \mathrm{c}$ reads 'Representative image of immunohistochemical analysis for RCN2 expression in adjacent nontumor tissues and tumor tissues of HCC patients.', while Figure 1d should read 'RCN2 level was examined by western blotting in paired HCC tissues. Relative signals are shown in the right panel.'
Second, in Supplementary Figure 2a, the connecting line in the right panel representing the comparison of cell growth between mock and restored QGY-7703 cell was not drawn correctly.

These errors have now been rectified. The html and online pdf versions have also been rectified, and now carry the corrected paper and Supplementary Figure.

The authors confirm that these errors have no impact on the conclusions of the paper and apologize for any inconvenience caused.

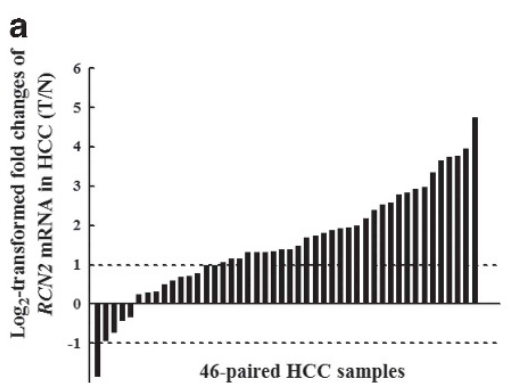

b
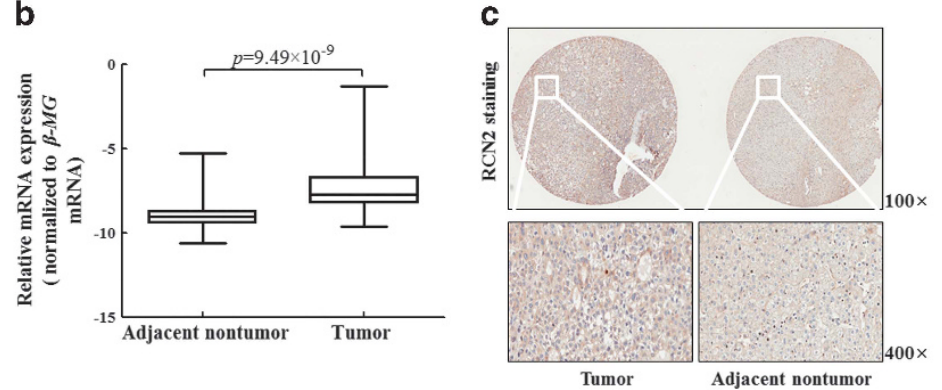

d
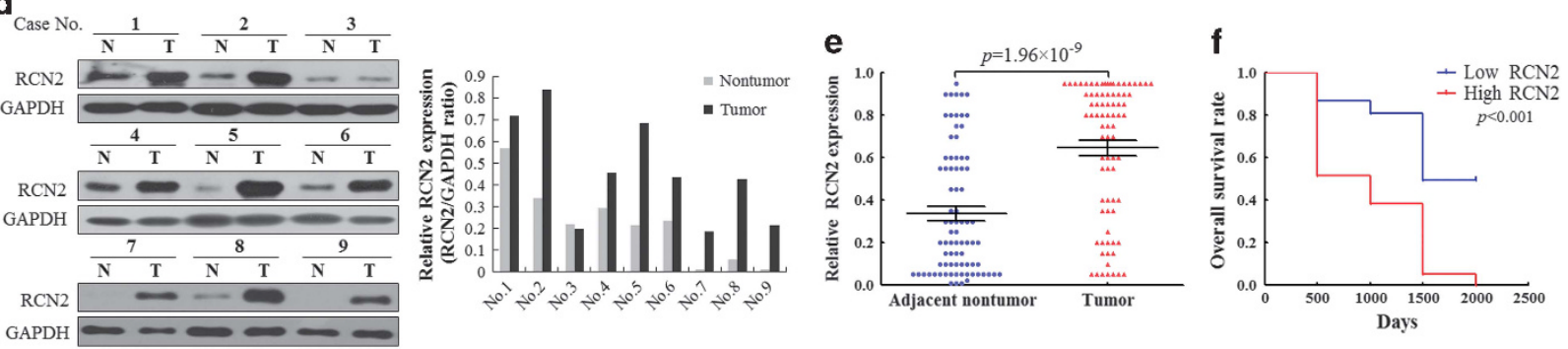

Figure 1. Upregulation of RCN2 expression in human HCC tissues. (a) Expression of RCN2 mRNA was detected in 46-paried tumor tissues and adjacent non-tumorous tissues from HCC patients by RT-qPCR. (b) Relative RCN2 mRNA level was higher in tumor tissues comparing with adjacent non-tumorous tissues. Student's t-test was performed. (c) Representative image of immunohistochemical analysis for RCN2 expression in adjacent nontumor tissues and tumor tissues of HCC patients. (d) RCN2 level was examined by western blotting in paired HCC tissues. Relative signals are shown in the right panel. (e) Relative of RCN2 expression of 80-paired HCC patients was evaluated by immunohistochemical analysis. (f) HCC patients with low RCN2 expression (tumor/adjacent non-tumor $<1$ ) exhibited better survival rate. 
a
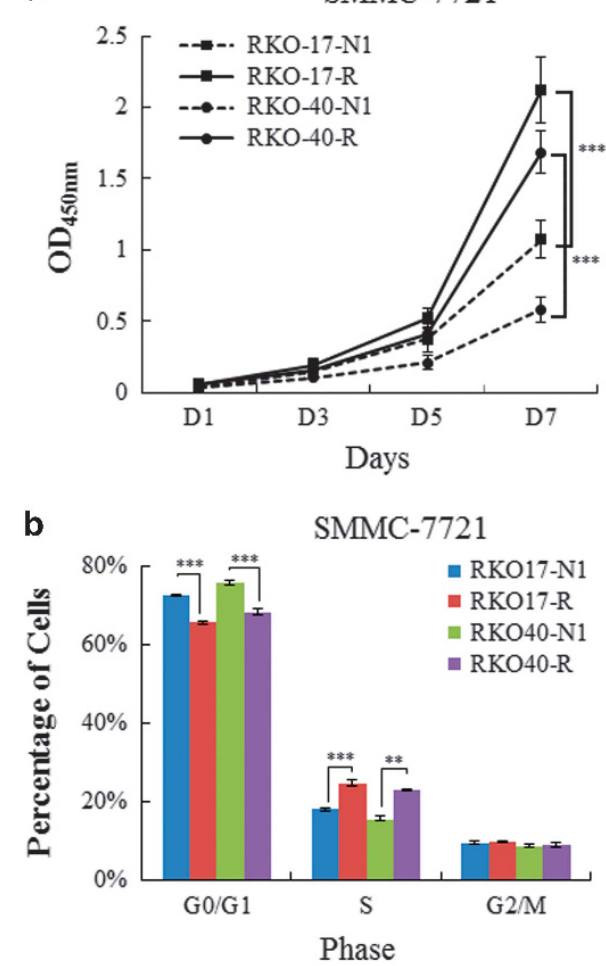

c

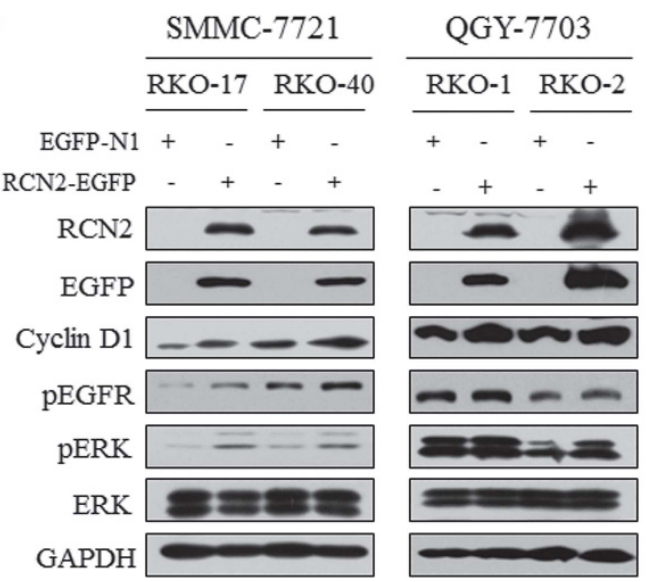

QGY-7703
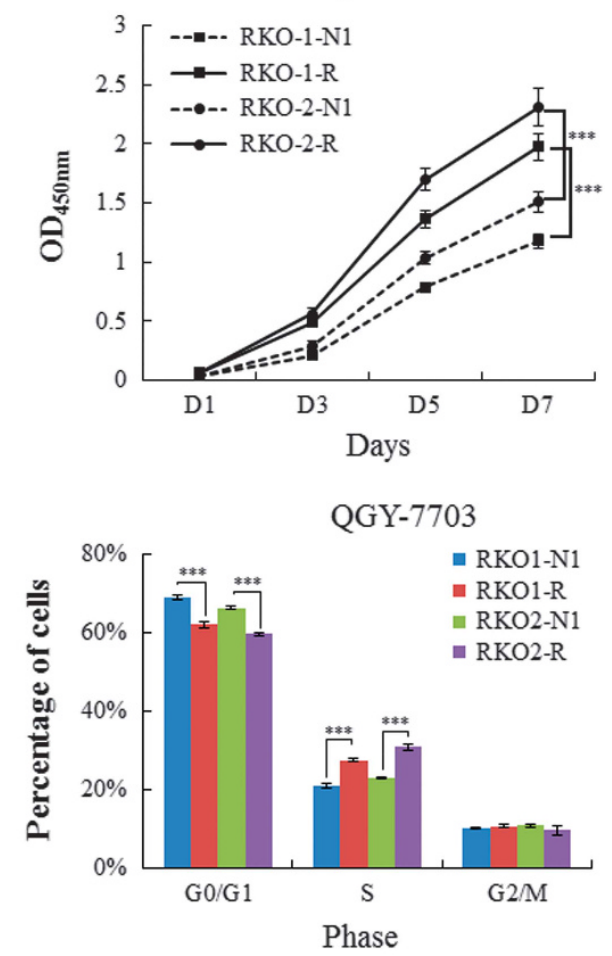